\title{
14. NO MORE SUPERHEROES ... ONLY AVATARS? SURVIVAL ROLE PLAY IN ENGLISH POST COMPULSORY EDUCATION
}

\section{BACKGROUND}

Developments such as the incorporation of colleges in England and Wales in $1993^{1}$ had a fundamental influence on the post-compulsory education (PCE) sector by creating a dramatic transformation in culture, ethos and style of management. Prior to this, both managers and tutors had a high degree of autonomy and were given significant freedom in the way they organised their working lives. However, the introduction of data driven efficiency measures and the increased surveillance of professional activity triggered a significant change in both professional role and professional identity and has been referred to as the terrors of performativity (Ball, 2003).

Within the whirlwind of change, many organisations were in a state of flux. They had to contend with new funding mechanisms and subsequent cuts to their budget, as well as prepare for influential judgements on their performance by organisations such as the government's inspectorate of education, commonly known as Ofsted. This presented a range of new challenges which were 'supported' by a plethora of new guidelines, systems and processes and the result was described by Coffield as:

A sector where the government had to establish a Bureaucracy Reduction Group to deal with the effects of its own hyperactivity in spawning so many new policies, initiatives, qualifications, institutions, partnerships, targets, priorities, ambitions and aspirations that those trying to enact their proposals became overwhelmed with the paperwork. (Coffield, 2008, p. 43)

For a new tutor entering the profession, this presented a somewhat muddled picture of the professional role and identity; on the one hand, there were clear guidelines relating to processes and the 'technical' aspects of the role on the other, somewhat conflicting information from experienced colleagues who contested the imposed changes.

For teachers, one significant outcome of the changes was the value placed on the skill or craft of teaching above other aspects of the role. This focus created a much narrower professional identity and neglected the wider aspects of the role, potentially leading to a more defined perception of the types of professional development which were considered relevant. 
According to the European Commission (2013), a teacher's role should include both teaching and teacher competencies. The former being those things associated with the craft of teaching and the latter encompassing the need to reflect, evaluate and work collaboratively in the wider professional community, recognising this as a body of knowledge which exists beyond the place of work. This view acknowledged teaching as a multifaceted career and provided a systemic view of teacher professionalism which could be likened to the notion of democratic professionalism (Sachs, 2001).

Despite the most significant of these changes having taken place over 20 years ago, there still remains some confusion around the purpose and extent of the PCE tutor's role and this is mirrored in the roles undertaken by middle managers (Thompson \& Wolstencroft, 2013). Indeed, there is evidence to suggest that such confusion has led to a sense of conflict between initial perceptions of a particular role and actual practice and has resulted in both tutors and managers leaving the sector or even the profession itself (Chambers \& Roper, 2000; Thompson \& Wolstencroft, 2013). This illuminates what has been described as the 'disjuncture between official rhetoric of lifelong learning and the experiences of those working and studying in English Further Education' (Avis \& Bathmaker, 2005, p. 61).

Although a number of the problems associated with entering the PCE teaching profession and undertaking management roles within it have been documented (Thompson \& Wolstencroft, 2012, 2013; Spenceley, 1997; Avis \& Bathmaker, 2007), this is not the complete picture. There are many new tutors and managers who had not only survived the process of change but enjoyed the challenge and found specific strategies to overcome the difficulties they were presented with (Thompson \& Wolstencroft, 2012, 2013).

Within this chapter, we will explore the challenges and professional identities of new tutors and managers within PCE as well as the strategies they employ to cope with the individual demands of their jobs.

\section{LITERATURE}

Attempting to define the roles and responsibilities of either a tutor or a manager within post compulsory education in England is not a simple task. Reece and Walker (2003), writing in one of the most popular textbooks of the early twentyfirst century, devoted 15 pages to describing the tutor's role, covering aspects such as facilitating learning, planning teaching, assessment and evaluation and yet, even this exhaustive list does not cover the breadth of tasks encompassed in the role. In addition, this description does not consider the context in which most tutors work or acknowledge the narrative of a sector where key performance indicators (KPIs) are dominant (Elliott, 2012).

The task becomes even more complicated when exploring the role managers within the sector. A role which was traditionally associated with managing curriculum has more recently been defined as being an 'active agent' in facilitating change 
(Alexiadou, 2001) in order to 'influence tutors' in a positive manner (Jameson, 2006). Whilst many middle managers maintain that this was one of the main drivers for taking on the role (Thompson \& Wolstencroft, 2013), the lived experience did not always concur. The changing nature of the sector driven by the KPI culture established the manager's role in a different light and viewed this as being much more restricted (Elliott, 2012; Briggs, 2006). Alternative evidence suggests that some managers, despite the more restrictive culture do manage to maintain a degree of autonomy (Page, 2015; Thompson \& Wolstencroft, 2013) but these managers do appear to be in the minority.

Professional development within PCE is often underpinned by once mandatory (and now 'strongly encouraged') courses such as those leading to the Certificate in Education or Postgraduate Certificate of Education (PGCE). As these qualifications are generic in nature, the complexities of the sector are not always addressed and the accepted norms advocated within the programmes do not necessarily conform with the more instrumental approach demanded by employers (Husband, 2015). Within such programmes, notions such as communities of practice (Lave \& Wenger, 1991) bear little resemblance to the practicalities of the job and as a result many new entrants do not always feel fully prepared for their role. This is true of both tutors (Simmons \& Thompson, 2008) and managers (Thompson \& Wolstencroft, 2013). Indeed, both groups have reported feelings of isolation and a lack of support from both mentors and peers (Spenceley, 1997). Such isolation can manifest itself in many different ways such as feelings of stress, uncertainty and in some cases, a sense of being in the wrong profession (Briggs, 2007; Robson, 1998).

The difficulties identified above have been exacerbated recently due the reduction in funding for the sector. This reduction, estimated at a total of $13.4 \%$ over 3 years (Chowdry \& Sibieta, 2012), has resulted in a decline in the number of tutors in the sector (LSIS 2013), a decrease in the resources available and as a consequence increased pressure to perform on those who are left, creating a situation whereby 'those running curriculum departments will mainly be judged by student outcomes' (Briggs, 2001, p. 13). Inevitably the necessity to do more with less may take many teaching staff outside of their 'comfort zone' and as described by Jameson (2006) bring to light the 'darker side' of leadership practice when excessive pressure is put on staff, in some cases leading to bullying which impacts on the health and wellbeing of those involved.

Within this context, it is easy to see how many tutors and managers may face a number of dilemmas within their professional activities particularly when asked to undertake activities which challenge their professional values or for which they feel they have had no preparation. Potentially such dilemmas provide an opportunity to reflect on and transform practice (Mezirow, 2003), however, this is not always the case, particularly in environments where staff feel unsupported (Segal, 2006) and indeed in many cases it merely causes increased stress and feelings of being under pressure.

Educational establishments have taken different approaches to interpreting their staff's needs for support (Clandinin, 2008). This has been borne out by this 
research which illustrated the ways in which support was interpreted by both organisations and the individuals within them. The move to a teaching role from a previous career and subsequently to a management role, is a transition that can entail a significant amount of anxiety and has the potential to impact on a person's life both inside and outside of the workplace. Previous studies (Briggs, 2003, 2006) found that employees felt alienated from their jobs and under extreme pressure from managers. Whilst many find effective coping strategies, a minority turn to ways of coping that might be described as unhealthy, with excessive alcohol consumption and reliance on medication being reported (Jameson, 2006).

The way in which support for employees is implemented is also interpreted differently within establishments. For some establishments, formal mechanisms have been put in place. Within the compulsory sector, the concept of PPA (planning, preparation and assessment time) was introduced to ensure that teachers had a greater work/life balance. Although sometimes viewed as a 'sticking plaster' rather than a solution to deeper problems facing the profession (Hammersley-Fletcher \& Lowe, 2013). Within PCE the focus is firmly placed on addressing the consequences of concerns and although access to additional services, such as a college approved counsellor or healthcare programme is sometimes provided, there is little acknowledgement that staff may need assistance in coping with the emotional aspects of their jobs.

\section{METHODOLOGY}

A case study approach, combined with semi-structured interviews was used in order to compare two diverse organisations within the post compulsory education sector in England. Organisation A is a military training establishment whilst organisation B is a College of Further Education specialising in the Creative Arts. Both organisations have a reputation for innovation and espoused values which encompass the support and well-being of staff.

A representative cross section of participants was selected using a purposive sampling technique. In each organisation, a senior manager in charge of the training and development of staff was interviewed along with a selection of middle managers. In addition to this tutors were interviewed. To ensure that the article reflected the views of those new to the sector, tutors interviewed were all currently completing their initial teacher training qualification.

Once the results from the initial sample had been examined, follow up forums were carried out to share these findings with a cross section of staff. The main objective of this was to gain insight into what could be done to address the issues highlighted.

The sample contained two managers (one senior) interviewed and six tutors in organisation A, whilst in organisation B there were six tutors and three managers (again one senior manager). 
Semi-structured interviews took place in October and November 2015 and the follow up forums were in June 2016. These were used to provide a structure as well as an opportunity to explore specific responses. All interviews were transcribed and analysed to identify common themes. Findings have been structured according to themes drawn from the data for both organisations.

\section{FINDINGS}

\section{'Bestowed'Professional Identities}

Participants from both organisations described their individual roles in relation to their official job title rather than adopting more generic labels such as 'teacher', 'tutor' or 'manager'. In this sense, professional identity seemed to be something that was bestowed, rather than claimed and was translated into labels such as 'instructor ... Lecturer in ... or Curriculum Manager for ...'. In addition, there appeared to be limited evidence that individuals considered themselves to be part of a wider professional community and reference was not made to the overall profession, indeed some responses deliberately diminished the description of the role, for example: 'I think the perception is it is professional ... so I will go with that'.

Tutors in both organisations appeared to operate within small, self-contained units, rather than a broader environment. This was particularly evident in organisation B where tutors operated in discrete departments organised according to subject specialism or whether they were teaching on 'FE' or 'HE' courses. This finding is not unusual and historically is evident in the caricatures associated with certain subject groupings within FE, clearly evident in the 'two cultures' split between practical and academic subjects outlined by Gleeson and Mardle (1980).

Within organisation A, professional identity was even more removed from the overall profession, as most participants described their identity in terms of primary and secondary roles, the primary roles being firmly placed within the organisation rather than the wider profession. 'I am a soldier first of all, then an intelligence officer', although this participant was currently employed within a teaching role, this title was not used in any description. Others referred to themselves as 'subject matter experts' or 'intelligence officers' (titles used within the organisation) with the only concession to the teaching profession being use of the word 'instructor'.

What united both organisations was a general feeling from tutors that their job was being de-professionalised by the introduction of a conformist approach to teaching. This was illustrated by a tutor in organisation B: 'I feel they are telling you how they want you to teach and I want to develop my own way .... I feel like there is a very narrow view of what teaching is'. However, two tutors in organisation B, (both working within the HE section of the organisation), presented an overwhelmingly positive image of the organisation and did not outline any such restrictions on how they approached the teaching role. 
Within organisation A, tutors operated within even stricter constraints including the requirement for PowerPoint presentations and resources to be approved before being used for teaching sessions. The process of changing things for individual lessons or groups was viewed as long and laborious and the consequence was that participants tended to complain about the system but go along with it.

The evidence presented in the interview responses did suggest that professional identity was not something that participants felt they had control over. Likewise, notions of professionalism seemed, in both organisations to be intertwined with the approaches advocated at an organisational level. In both cases these approaches leaned towards a competency model with a focus on teaching competencies rather than teacher competencies and did not correspond with more democratic approaches to professionalism. As a result, tutors seemed to view their roles in much more narrow terms. The response from managers corresponded to this by outlining their roles and professional identity as being in line with their roles within the organisation, again evidencing acknowledgement of the constraints imposed by the organisation but not questioning these. One manager, when describing his role, outlined the difficulties but did not question the reasons for them: ' ... it has become a running joke within the team. Because it is normally a year before someone packs it in'. This participant also showed awareness of the impact of quality assurance measures: 'We have a meeting once a week where we discuss things that are affecting data ... sometimes it is bad news that I have to pass down to my team'; but readily accepted this as part of his role and described it as a form of support. The most noticeable difference to this was responses from managers at a more senior level who did raise questions about how systems and processes had created blocks to progress:

For example, something that winds me up hideously is that we don't offer release to our teacher trainees ... and that bothers me because I think they probably need it even if it's not hour for hour ... we don't that's kind of the rule and mainly that's because it's so efficient and it's so calculated ... so because everyone is doing up to 23 hours a week there's a calculation as to how many staff you need and then if you just say, 'could we just knock an hour off everyone' you are knocking an hour of 60 people and suddenly [financially] that's three members of staff ...

\section{Expectation Versus Reality}

Previous studies have suggested that tutors do not feel prepared for the realities of working within the post compulsory education sector (Wallace, 2002; Spenceley, 2007; Thompson \& Wolstencroft, 2012). In each of these studies, the lived experience of the role was perceived as being less rewarding than the expectations. The data from this research did not replicate previous findings as most participants had a clear insight into the role prior to starting to it. This was particularly evident in organisation A: 'I was already warned that the course was dated so I had the sceptical side of me 
as well was thinking what can I change when I get there?' and '... I would enjoy the teaching side of it but would be hampered by bureaucracy ...' Yet despite this prior knowledge, most tutors were frustrated by certain aspects of the role, specifically the need to ensure that everything was enshrined in paperwork: 'It can really get me down sometimes, the endless meetings with almost no outcomes and the paperwork filling and all that sort of stuff'. Similarly, tutors expressed concerns about what they saw as a 'no fail' culture within their organisations. These two quotes come from firstly, organisation A, then B:

Firstly 'Nowadays, the minute I say someone is not good enough I am challenged' then 'If a student isn't doing work, its more work for me rather than for them. You have to do a tutorial and then type it up, phone their parents, write an action plan and I can do all of that and then the students still doesn't do anything, it is frustrating'.

Whilst most participants did have some insight into their roles at the outset, they were often surprised by the extent of the issues they encountered. For tutors these issues were created by college systems and processes. Conversely, for managers the problems associated with staff seemed to present the most concerns including problems with absence and performance management. Accompanying this was the almost constant change most managers had to contend with as outlined by a Senior manager from organisation B: 'My expectation has almost become Heraclitian, I just expect it to be different all the time'. The same manager also had their own particular view on the main causes of stress "Was it Sartre who said "Hell is other people"'?

\section{Avatars as Agents of Change}

The notion of the teacher as an active agent denotes a group of professionals with the ability to make choices and find a balance between personal preferences, student needs and organisational aims. This description suggests that agency is a form of personal power and akin to Bourdieu's notion of 'habitus'. In this sense, agency is something which is not simply free will or a response to structures but an interplay between the two (Bourdieu, 1984). From a pragmatic perspective, agency might be defined as the ability of individuals to 'critically shape their responses to problematic situations' (Biesta \& Tedder, 2006, p. 11). Within this research, the concept of agency was explored in relation to tutors and managers' perceptions of professional identity and the ways in which roles were enacted within a given context.

The resistance to the changes imposed on the further education sector post incorporation have been well documented (Ainley \& Bailey, 1997; Shain \& Gleeson, 1999) and clearly outline the conflicts found between teachers' ideas about their professional roles and the 'ideals' imposed through the adoption of a more marketised approach. As a result, teachers' work is highly controlled through management systems, often in ways which are perceived to have a negative impact on staff. Examples of this were presented in the initial interviews and the follow up 
forums and were usually recognised in the form of expected outcomes such as targets or performance measurement. The pressures did not appear to have diminished between the two parts of the research and in some cases the situation was viewed more pessimistically, as one participant from organisation B explained:

'I think our situation has actually got worse. Since being asked all of those questions I would have so many more examples to go with that ...' This was supported by a colleague: 'The fact of the matter is ... challenging is a lot of effort and when you are already really fatigued mentally and physically, that challenge seems like an impossible task ...'

Indeed, the examples provided from both organisation A and organisation B represented groups of people who were well aware of their situation and somewhat resigned to it for survival reasons.

If the system doesn't do anything to support you time and again it's like well ... why try and beat the system when it's never going to work because there's no other heroes above you.

and: The [organisation] is terrible for it because they don't like 'superheroes' or people who fight back. if you fight back ... you won't get promoted ... if you don't get promoted you won't get into the managerial positions and the people in the managerial positions are the 'yes men' ...

The 'final resignation' came from one of the most experienced tutors in the group:

... people are frightened of losing their jobs so they are therefore conforming to the rules ... when you become stressed you revert to a situation where you stick to the rules or a process so that you don't actually feel the stress quite so much. So, if you just keep ticking the boxes then you can keep the stress levels down.

These findings contradict views that teachers are able to be agents of change with an independent ability to act (Priestley et al., 2012), instead they depict a scenario of following orders and 'fitting in' perhaps representative of the accepted culture of conformity present within both organisations. The responses also highlight a onedimensional view of agency which perhaps reduces the notion to its simplest terms.

Taking Emirbayer and Mische's (1998) view, agency should be seen as three dimensional with iterational, projective and practical-evaluative dimensions. The iterational taking into account professional histories, in this context the ways in which things have been, or are currently done within the organisations; the projective taking a future orientation, based on the facility to imagine alternative possibilities and the practical-evaluative giving consideration to the context of past history and dealing with the events of the moment. If we examine the data from this perspective, the picture is a little different as illustrated by the following responses; in organisation A, where tutors were often training future colleagues, there was clear appreciation of the underpinning reasons for current processes: 
'The management work in their own little silos where they know they have got to get a certain number of people through so that's what they are concerned with. We are not going to be trainers for ever ... we will go back and do our normal jobs ...'. Whilst recognising the data driven reasons underpinning processes and the ways in which staff turnover reinforced norms of practice, there was also acknowledgement of the importance of, and potential for a change: '.. . and that person who we thought should have failed ... you could end up working with them ... so we should probably take that view and get rid of them because otherwise we are putting them into this trade group'.

In organisation $\mathrm{B}$, where most senior managers did not teach, respondents were also aware of the reasons for current approaches and showed clear appreciation of the potential for change:

'... the reason that happens is that as managers they are not in that everyday routine of what you are experiencing ...' and 'It's a bit like having advice on your career and your love life from your grandparents ... cos (sic) everything they know was relevant like (sic) 40 years ago ...' These responses highlight a shared understanding of the reasons for stagnation in processes and led to suggestions about steps which might be taken to generate greater understandings and potential improvements:

If we turn it around real quick ... instead of love life ... think a war ... which is almost the same thing ... people on the front line, they will have their radios ... (and) can basically explain "this is the path that we have got to take" they have to help the commanders ... and if that's not taking place ... they keep on making the same mistakes.

These responses illustrate that teacher and manager agency cannot simply be seen as personal capacity in the form of the 'superhero' who fights a given cause but is in fact contextually bound and requires recognition of all factors which influence that context. To promote agency for professionals within the post compulsory education sector is not only a matter of professional development or the provision of learning spaces but also requires consideration of the current cultures and structures within which the sector operates.

It was evident that many of the respondents did use their agency in ways which had a positive impact on their colleagues or students; one clear example of this could be described as 'protective mediation' (Osborn et al., 1997), in this case the tutor was well aware of the organisation's 'rules' in relation to student attendance:

My best student is straight distinctions for everything, has attendance of 60 odd percent and everyone else can look at these statistics and go "oh that's pretty awful ... what's being done to punish this one?" ... but they are literally outperforming in every other thing you ask them to do. 
By not 'punishing' this student the tutor is acting agentically in order to protect them from aspects of organisation policy which are considered unhelpful or even harmful. The same tutor was aware that these actions were viewed differently by those in more senior positions and interpreted as something akin to wayward, rather than agentic behaviour:

the problem is I am then being told by 'higher ups' in our organisation that I am taking too much of myself into that room and I am making too much of a personal bond with the students as was pointed out to me earlier in the week ... after five years now I am still treated like the unreliable child.

\section{Support Strategies and Coping Strategies}

It is clear that the organisations within this study recognise the need to support their staff and there were a number of measures put in place to mitigate against the pressures that tutors and managers experienced. These included additional training and in some cases mentoring. Although these efforts were acknowledged by participants, the general feeling was that the strategies implemented were focussed on organisational, rather than professional aims and as a result were of limited value. Whilst several participants recognised the value of the organisation providing financial support for training, they were also aware that this was overtly directed by more senior managers:

'... so the hierarchy tell us what we should be doing, how we can develop and give us opportunities to do so'. In some examples there was an element of cynicism which suggested that espoused support strategies may have had more to do with creating the right image than supporting individuals, articulated succinctly by one tutor from organisation A: 'It looks good on paper'.

Within both organisations feedback from participants evidenced the importance of informal support mechanisms which usually revolved around peers. These had some similarities to the concept of communities of practice (Lave \& Wenger, 1991) in that all participants had shared common interests usually to do with teaching or managing education. One difference was that, with the exception of teacher training, none of the participants appeared to be involved in communities of practice beyond the organisation.

In some cases, support was linked directly to professional development, for example learning through peer observations or discussing approaches to teaching, opportunities usually facilitated within teacher training programmes. In other examples the support had more to do with managing emotions and colleagues were seen as a sympathetic ear. A minority of respondents did mention the importance of 'individual space' but the majority were enthusiastic about the support they received from their peers, for example: 
... just sit in on each other's lessons and sit down now and again with a brew and iron out any problems.

\section{Space to Learn}

The concept of learning spaces was interpreted in two distinct ways; firstly, a physical space which was removed from the work environment; secondly, the recognition that space in the work timetable would be the most important learning space. In many cases, the examples given were similar to the more traditional communal 'staffrooms' in effect, a place where people could get away from the stresses of the job. Some participants talked about the practicalities of having a space to get away from the paraphernalia associated with modern teaching: 'A place where I can't be hounded by phone calls', whilst the comments of others were more closely linked to the concept of a community of practice: 'A place with peers to bounce ideas around'. A common theme was that both tutors and managers wanted a 'safe' place where they could discuss things without risk of censure, as outlined by a manager in organisation B '... where you can say the unsayable'.

This final point was reinforced by the differences in the data presented in the separate parts of this research. Within the individual interview transcripts there is evidence of a group of people who felt dominated by the systems and processes in place. Within the group forums, the sharing of thoughts and ideas led to greater clarity in relation to the drivers present for those working within the sector and reference was made to a philosophical, rather than corporate approach: 'There has to be a genuine desire to make a change to see students and think ... they are not numbers and they are not just sheep ... and thinking that "I want these people to become something" ... that drives everything'.

The provision of teacher education was also considered as a possible learning space with the ability to improve professional practice as well as teacher agency, yet this too was questioned in relation to its impact; as highlighted by one participant:

competence based teacher training programmes breed competence based teachers ... if that's what they think teaching is about .... Jumping through hoops and ticking boxes ... then that's what you're going to get.

The data presented in the forums suggest that that this view might be simplistic. All of the participants were aware of the need to successfully complete teacher training qualifications as part of their professional development but also recognised the opportunity this presented to analyse current processes and practices. When gathered as a collective, participants from both organisations articulated a drive and passion for 'making a difference' to the lives of their students, despite the limitations imposed within the individual organisations. The time and space to share ideas, often encapsulated within a teacher training class was viewed as a vehicle for this and provided the space within which to explore alternative approaches. 


\section{CONCLUSIONS}

Previous research has suggested that many tutors and managers have fought against the 'terrors of performativity' (Ball, 2003) often through forms of strategic compliance (Shain \& Gleeson, 1999). Our own research, conducted 4 years ago, into the roles of curriculum managers in the sector provided a number of examples of this and depicted this group as 'superheroes' driven by their personal values rather than those imposed by the organisation (Thompson \& Wolstencroft, 2013). This non-conformist approach was not evident in the data presented here, in fact, whilst tutors and managers in both organisations recognised and often resented, the constraints placed upon them, they did display consistently compliant approaches, albeit 'reluctant compliance'.

This was most apparent in the ways in which participants described their professional identity as something which was 'bestowed' upon them by the organisation, rather than a profession in its own right. It is clear that for the tutors in this study their roles were directed by teaching, rather than teacher competencies (European Commission, 2013) placing an emphasis on the more technical aspects of the role and references made to some of the control measures which had been put into place within both organisations such as prescribed approaches to teaching, checks on data, limited control over resources, did emphasise the role of teaching as a craft rather than a profession. Likewise, managers provided evidence of introjecting the values of the organisation by articulating a need to comply with organisational norms, even to the extent of seeing QA measures such as checks on data, as a form of support.

Most participants in this research took up their roles post incorporation and as a result were not familiar with the professional context prior to the impact of marketisation. The resulting segregation, created by increased competition has increased the power of individual organisations to such an extent that the wider profession does not seem to be recognised. This is particularly apparent for tutors who viewed their professional identities in line with their formal titles or primary roles within the organisation and their agency as being governed by organisational norms. Notions of collegiality beyond the immediate workplace do appear to have become alien and were not considered as a form of personal learning by most of the participants. Despite the more limited view of collegiality, all participants recognised and valued the ways in which their immediate colleagues offered support and sought informal ways of accessing this for professional development and emotional sustenance.

A dominant finding within the interview data is the overall influence of individual organisations to design and dictate professional identity to such an extent that individuals and professional groups appeared to be dominated by given roles. The evidence suggests that the strategic compliance which previously allowed individuals to meet organisational aims whilst guided by their own professional values, appears to have been replaced by high levels of reluctant compliance with complete 
awareness of how the organisation's management processes were controlling teacher and manager agency.

When talking collectively, as evidenced by the forum data, tutors indicated higher levels of agency and recognised the ways in which they could effect change (Priestley et al., 2012). Although tentative, this did illustrate a willingness to take action which may support personal and professional values over organisational norms.

In the world of computer games, the Avatar is an icon which plays out a particular role, in Hinduism the manifestation of a deity released on earth ... in the world of post compulsory education, a reluctant conformer ... or an embodiment of potential change?

\section{NOTE}

1 The Incorporation of colleges refers to the FE-HE Act 1992, which released FE institutions from the control of local authorities and gave them responsibilities of self-regulation and independence.

\section{REFERENCES}

Alexiadou, N. (2001). Management identities in transition: A case study from further education. Sociological Review, 49(3), 412-435.

Avis, J., \& Bathmaker, A. (2007). 'How do I cope with that?' The challenge of 'schooling' cultures in further education for trainee FE teachers. British Educational Research Journal, 33(4), 509-532.

Ball, S. (2003). The teacher's soul and the terrors of performativity. Journal of Education Policy, 18(2), $215-228$.

Biesta, G. J. J., \& Tedder, M. (2006). How is agency possible? Towards an ecological understanding of agency-as achievement (Working Paper 5). Exeter: The Learning Lives project.

Bourdieu, P. (1984). Distinction: A social critique of the judgement of taste. London: Routledge.

Briggs, A. (2001). Middle managers in further education: Exploring the role. Management in Education, 15(4), 12-16.

Briggs, A. (2006). Middle management in further education. London: Continuum.

Briggs, A. (2007). Exploring professional identities: Middle leadership in further education colleges. School Leadership and Management, 27(5), 471-485.

Chambers, G., \& Roper, T. (2000). Why students withdraw from initial teacher training. Journal of Education for Teaching: International Research and Pedagogy, 26(1), 25-43.

Chowdry, H., \& Sibieta, L. (2012). Trends in education and schools spending. London: IFS.

Clandinin, D. J. (2008). Creating learning spaces for teachers and teacher educators. Teachers and Teaching: Theory and Practice, 14(5-6), 385-389.

Coffield, F. (2008). Just suppose teaching and learning became the first priority. London: Learning and Skills Network.

Crawley, J. (2012). 'On the brink' or 'designing the future'? Where next for lifelong learning initial teacher education? Teaching in Lifelong Learning: A Journal to Inform and Improve Practice, 4(1), 2-12. Retrieved October 27, 2015, from http://dx.doi.org/10.5920/till.2012.412

Department for Business Innovation and Skills. (2012). Professionalism in further education: Interim report. London: BIS.

Elliott, G. (2012). Policy, performativity and partnership: An ethical leadership perspective. Research in Post-Compulsory Education, 17(4), 423-433.

Emirbayer, M., \& Mische, A. (1998). What is agency? The American Journal of Sociology, 103, 962-1023.

Etzioni, A. (Ed.). (1969). The semi-professions and their organization: Teachers, nurses, social workers. New York, NY: Free Press.

Gleeson, D., \& Mardle, G. (1980). Further education or training? A case study in the theory and practice of day release education. London: Routledge \& Kegan Paul. 


\section{A. THOMPSON \& P. J. WOLSTENCROFT}

Hammersley-Fletcher, L., \& Lowe, M. (2013). In K. Safford, M. Stacey, \& R. Hancock (Eds.), Small scale research projects in primary school. Abingdon: Routledge.

Husband, G. (2015). The impact of tutors' initial teacher training on continuing professional development needs for teaching and learning in post-compulsory education. Research in Post-Compulsory Education, 20(2), 227-244.

Jameson, J. (2006). Leadership in post compulsory education. Abingdon: David Fulton.

Lave, J., \& Wenger, E. (1991). Situated learning: Legitimate peripheral participation. Cambridge: Cambridge University Press.

Learning and Skills Improvement Service. (2013). An analysis of the staff individualised record data, 2011-12. Coventry: LSIS.

Mezirow, J. (2003). Transformative learning: Theory to practice. New Directions for Adult and Continuing Education, 74(1), 5-12.

Orr, K. (2012). Coping, confidence and alienation: The early experience of trainee teachers in English FE'. Journal of Education for Teaching, 38(1), 51-65.

Page, D. (2011). Fundamentalists, priests, martyrs and converts: A typology of first tier management in further education. Research in Post-Compulsory Education, 16(1), 101-121.

Priestley, M., Biesta, G., \& Robinson, S. (2015). Teachers as agents of change: An exploration of the concept of teacher agency (Working Paper No. 1). Stirling: Teacher Agency and Curriculum Change, University of Stirling.

Reece, I., \& Walker, S. (2003). Teaching, training and learning a practical guide (5th ed.). Sunderland: BEP.

Robson, J. (1998). A profession in crisis: Status, culture and identity in the further education college. Journal of Vocational Education and Training, 50(4), 585-607.

Sachs, J. (2001). Teacher professional identity: Competing discourses, competing outcomes. Journal of Education Policy, 16(2), 149-161.

Segal, S. (2006). The existential conditions of explicitness: An Heideggerian perspective. Studies in Continuing Education, 21(1), 73-89.

Shain, F., \& Gleeson, D. (1999). Under new management: Changing conceptions of teacher professionalism and policy in the further education sector. Journal of Education Policy, 14(4), 445-462.

Simmons, R., \& Thompson, R. (2008). Creativity and performativity: The case of further education. British Educational Research Journal, 34(5), 601-618.

Spenceley, L. (2007). Walking into a dark room: The initial impressions of learner-educators in further education and training. Journal of Further and Higher Education, 31(2), 87-96.

Thompson, C. A., \& Wolstencroft, P. (2013). Promises and lies. Journal of Further and Higher Education, $38(1), 1-18$.

Thompson, C. A., \& Wolstencroft, P. (2014). Give 'em the old razzle dazzle: Surviving the lesson observation process in further education. Research in Post Compulsory Education, 19(3), 261-275.

Wallace, S. (2002). No good surprises: Intending tutors' preconceptions and initial experiences of further education. British Educational Research Journal, 28(1), 79-93.

Williams, J., \& Jacobs, J. (2004). Exploring the use of blogs as learning spaces in the higher education sector. Australasian Journal of Educational Technology, 20(4), 232-247.

Carol A. Thompson

University of Pennsylvania

Philadelphia, PA, USA

Katy J. Wolstencroft

Leiden University

Leiden, the Netherlands 